\title{
Extent of Utilization of the Available Technology Resources and Facilities of Nursing Faculty and the Extent of Benefits to Students in the Teaching and Learning Process
}

\author{
Mae Joy B. Penaflor-Espinosa \\ Woosong University, Daejeon, Republic of Korea \\ maejoyespinosa426@yahoo.com
}

\begin{abstract}
This is a descriptive research study which determined the extent of utilization of the available technology resources and facilities of nursing faculty and the extent of benefits to students of integrating technology in the teaching and learning process. The nursing faculty had moderate utilization to technology-based teaching tools wherein powerpoint presentation was highly utilized. The extent of benefit to students in the integration of technology by the nursing faculty in teaching and learning process was also moderate. It made the students happy, allowing them to enjoy varied learning activities, and has helped in communication and collaboration. The utilization of technology enhances students' motivation to learn and are more likely to have an enjoyable and meaningful learning experiences. This research study concludes that the integration of technology in nursing education can make a measurable difference in teaching and in the learning process. Recommendations focused on enhancement capability-building programs in utilizing technology, creative lesson planning and blended learning, improving school resources and facilities, and adaptation to technological use in nursing education.
\end{abstract}

Keywords: Technology Integration, Extent of Benefits to Students in Utilizing Technology, Extent of Utilization of Technology Resources, Nursing Faculty Use of Technology

\section{Introduction}

Technological advancement has greatly influenced the higher educational institutions in the $21^{\text {st }}$ century. The information and communication technology (ICT) has become one of the basic building blocks of modern society (Division of Higher Education, UNESCO, 2002).

In nursing education, there has been a significant increase in the use of technology. Information and communication technologies (ICTs) are emerging in new study plans of the nursing career in recent years (Fernández-Alemán, García, Montesinos, MarquésSánchez, Darkistade, \& Rivera, 2014) and have opened the door to many new teaching approaches for nurse educators (Axley, 2008).They must be able to design, develop, and evaluate learning experiences based on new technologies (Fernández-Alemán et al., 2014). Moreover, there is a need to integrate technology where the curriculum consists of an overwhelming amount of essential learning material wherein the student must have the advanced knowledge and critical thinking skills necessary to act with accuracy in lifeand-death situations. Nursing faculty have responded to these increasing educational needs through the use of technological formats for both classroom and clinical instruction (Iverson, Ball, Harms, Murcek, Woods, \& Young, 2016) and it requires an educator who is prepared to facilitate an effective learning experience (Axley, 2008).

Received (October 25, 2017), Review Result (December 19, 2017), Accepted (January 10, 2018) 
Transforming evidence based pedagogies such as student collaboration, mastery learning, feedback, meta-cognition and self regulation (Educational Endowment Fund, 2016 cited by Stec 2017) can be accomplished through the thoughtful integration of technology in the classroom. The incorporation of technology in the classroom can be quite useful, as "the use of virtual environments for collaboration and learning can result in unprecedented flow of ideas, leading to higher levels of productivity" (Chandra, Theng, Lwin, \& Foo, 2009, cited by Brown 2011). Increased implementation of technology will increase students' comprehension of content and development of skills in such areas as analytical reasoning, problem solving, information evaluation, and creative thinking (AlHariri \& Al-Hattami, 2017).

In the Philippines, integration of technology in the teaching-learning process in nursing education has taken a lot of turns, and there has been a change of paradigm for the better. The researcher has observed that there is limited access to facilities and resources for the students as well as for the nursing faculty. Locally, only few studies have explored about the integration of technology in education. These observations highlight the necessity to investigate the nature of the integration of technology in the teaching and learning process in nursing education. The dearth of studies validate therefore the need to investigate the extent of utilization of the available technology resources and facilities of nursing faculty and the extent of benefits to students of integrating technology in the teaching and learning process.

\section{Objective of the Study}

This study determined the extent of utilization of the available technology resources and facilities of nursing faculty and the extent of benefits to students of integrating technology in the teaching and learning process.

\section{Methodology}

This study is a descriptive research, one-shot survey, conducted in 2015 among the 167 nursing faculty in six nursing schools in Western Visayas, Philippines, specifically, in the Provinces of Iloilo and Negros, Occidental. The six nursing schools were the top performing schools in the Philippine Licensure Examinations in 2013 and 2014. Respondents on the utilization and integration of available resources and facilities were the179 nursing faculty and the 218 fourth year nursing students.

The study has used a researcher-made questionnaire-checklist on the available technology resources and facilities which have been utilized by the nursing faculty and the extent of benefits to students of integrating technology in teaching and learning process. The information provided were treated highly confidential and used solely for research. Data gathered were processed and analyzed using the Statistical Package for Social Sciences (SPSS) version 17.

\section{Results and Discussions}

\section{The Extent of Utilization of the Available Technology Resources and Facilities of the Faculty in the Six Colleges of Nursing}

The data in Table 1 reveal that powerpoint presentation was highly utilized in College A $(M=4.00)$. The use of video clips, audiovisual slides and files, instructional videos, procedures, and documentations, online research works and updates, web-based assignments, projects, activities, and computer-based virtual simulations were utilized moderately while the giving of on-line quiz and tests $(\mathrm{M}=1.23)$ was of low utilization. 
Table 1. Extent of Utilization of the Available Technology Resources and Facilities of Nursing Faculty in College $A(n=30)$

\begin{tabular}{lll}
\hline \multicolumn{1}{c}{ ICT Tools } & Mean & \multicolumn{1}{c}{ Description } \\
& & \\
\hline Powerpoint Presentation & 4.00 & High utilization \\
Videoclips & 2.97 & Moderate utilization \\
Audiovisual slides/files & 3.27 & Moderateutilization \\
Instructional videos/procedures/documentation & 3.13 & Moderate utilization \\
Online research works/updates & 2.93 & Moderate utilization \\
Web-based assignments, projects, activities & 2.60 & Moderate utilization \\
Computer-based virtual simulations & 1.63 & Minimal utilization \\
Online quiz and tests & 1.23 & Low utilization \\
\hline
\end{tabular}

In College B, powerpoint presentation $(\mathrm{M}=3.86)$ was the most highly utilized by the nursing faculty. On the other hand, audiovisual slides and files $(M=3.36)$, instructional videos, procedures, documentations $(\mathrm{M}=3.05)$, video clips $(\mathrm{M}=2.95)$, online research works and updates $(M=2.91)$, virtual simulations $(M=2.91)$, and web-based assignments, projects, and activities $(\mathrm{M}=2.55)$ were moderately utilized, however, online quiz and tests $(\mathrm{M}=1.73)$ was of minimal utilization.

\section{Table 2. Extent of Utilization of the Available Technology Resources and Facilities of Nursing Faculty in College $B(n=22)$}

\begin{tabular}{|c|c|c|}
\hline ICT Tools & Mean & Description \\
\hline Powerpoint Presentation & 3.86 & High utilization \\
\hline Videoclips & 2.95 & Moderate \\
\hline Audiovisual slides/files & 3.36 & utilization \\
\hline Instructional videos/procedures/documentation & 3.05 & Moderateutilizati \\
\hline Online research works/updates & 2.91 & on \\
\hline Web-based assignments, projects, activities & 2.55 & Moderate \\
\hline Computer-based virtual simulations & 2.91 & utilization \\
\hline Online quiz and tests & 1.73 & $\begin{array}{l}\text { Moderate } \\
\text { utilization } \\
\text { Moderate } \\
\text { utilization } \\
\text { Moderate } \\
\text { utilization } \\
\text { Minimal } \\
\text { utilization }\end{array}$ \\
\hline
\end{tabular}

The data in Table 3 show that nursing students had experienced high utilization of technology like powerpoint presentation $(\mathrm{M}=4.0)$, audiovisual slides and files $(\mathrm{M}=3.92)$, video clips $(\mathrm{M}=3.73)$, instructional video, procedures and documentation $(\mathrm{M}=3.68)$, and web-based assignments, projects, and activities $(\mathrm{M}=3.51)$. Online research works and updates $(\mathrm{M}=3.38)$ and computer-based virtual simulations $(\mathrm{M}=3.16)$ were moderately utilized while online quiz $(\mathrm{M}=1.73)$ was used to a minimal extent only. 
Table 3. Extent of Utilization of the Available Technology Resources and Facilities of Nursing Faculty in College $C(n=37)$

\begin{tabular}{lll}
\hline \multicolumn{1}{c}{ ICT Tools } & Mean & \multicolumn{1}{c}{ Description } \\
& & \\
\hline Powerpoint Presentation & 4.00 & High utilization \\
Videoclips & 3.73 & High utilization \\
Audiovisual slides/files & 3.92 & High utilization \\
Instructional videos/procedures/documentation & 3.68 & High utilization \\
Online research works/updates & 3.38 & Moderate utilization \\
Web-based assignments, projects, activities & 3.51 & High utilization \\
Computer-based virtual simulations & 3.16 & Moderate utilization \\
Online quiz and tests & 1.73 & Minimalutilization \\
\hline
\end{tabular}

Table 4 is the extent of utilization of available technology resources and facilities of the nursing faculty in College D. The result show that power point presentation was highly utilized by the faculty $(\mathrm{M}=3.89)$ while online research works and updates $(M=3.05)$, web-based assignments, projects and activities $(M=2.95)$, audiovisual slides and files $(M=2.89)$, instructional videos, procedures, and documentation $(M=2.76)$, and video clips $(\mathrm{M}=2.63)$ were of moderate utilization. Computer-based virtual simulations and online quiz and test were the least utilized, as they obtained the lowest mean scores $(\mathrm{M}=2.13$ and 1.95 , respectively).

Table 4. Extent of Utilization of the Available Technology Resources and Facilities of Nursing Faculty in College $D(n=38)$

\begin{tabular}{lll}
\hline \multicolumn{1}{c}{ ICT Tools } & Mean & \multicolumn{1}{c}{ Description } \\
\hline Powerpoint Presentation & 3.89 & High utilization \\
Videoclips & 2.63 & Moderate utilization \\
Audiovisual slides/files & 2.89 & Moderate utilization \\
Instructional videos/procedures/documentation & 2.76 & Moderate utilization \\
Online research works/updates & 3.05 & Moderate utilization \\
Web-based assignments. projects, activities & 2.95 & Moderate utilization \\
Computer-based virtual simulations & 2.13 & Minimal utilization \\
Online quiz and tests & 1.95 & Minimal utilization \\
\hline
\end{tabular}

Table 5 shows the technology resources utilized by the nursing faculty in College E. According to the students, power point presentation $(M=3.90)$, audiovisual slides and files $(\mathrm{M}=3.75)$, were of high utilization by the faculty, while video clips $(\mathrm{M}=3.40)$, instructional videos, procedures, and documentation $(M=3.30)$, online research works and updates $(M=3.20)$, web-based assignments, projects, and activities $(M=3.05)$, and computer-based virtual simulations $(\mathrm{M}=2.65)$ were moderately utilized. The least utilized was online quiz $(\mathrm{M}=1.95)$. 


\section{Table 5. Extent of Utilization of the Available Technology Resources and Facilities of Nursing Faculty in College $E(n=20)$}

\begin{tabular}{lll}
\hline \multicolumn{1}{c}{ ICT Tools } & Mean & \multicolumn{1}{c}{ Description } \\
\hline Powerpoint Presentation & 3.90 & High utilization \\
Videoclips & 3.40 & Moderateutilization \\
Audiovisual slides/files & 3.75 & High utilization \\
Instructional videos/procedures/documentation & 3.30 & Moderateutilization \\
Online research works/updates & 3.20 & Moderate utilization \\
Web-based assignments, projects, activities & 3.05 & Moderate utilization \\
Computer-based virtual simulations & 2.65 & Moderate utilization \\
Online quiz and tests & 1.95 & Minimal utilization \\
\hline
\end{tabular}

The data in Table 6 show that nursing faculty had highly utilized power point presentation $(\mathrm{M}=3.90)$. They moderately utilized the audiovisual slides and files $(\mathrm{M}=3.46)$, video clips $(\mathrm{M}=3.04)$, instructional videos, procedures, and documentation $(\mathrm{M}=3.07)$, online research works and updates $(\mathrm{M}=3.01)$, and web-based assignments, projects, and activities $(\mathrm{M}=2.94)$. However, they had minimal utilization to computerbased virtual simulations $(M=2.31)$ and online quiz and test $(M=2.17)$.

\section{Table 6. Extent of Utilization of the Available Technology Resources and Facilities of Nursing Faculty in College $F(n=71)$}

\begin{tabular}{lll}
\hline \multicolumn{1}{c}{ ICT Tools } & Mean & \multicolumn{1}{c}{ Description } \\
& & \\
\hline Powerpoint Presentation & 3.90 & High utilization \\
Videoclips & 3.04 & Moderate utilization \\
Audiovisual slides/files & 3.46 & Moderate utilization \\
Instructional videos/procedures/documentation & 3.07 & Moderate utilization \\
Online research works/updates & 3.01 & Moderate utilization \\
Web-based assignments, projects, activities & 2.94 & Moderate utilization \\
Computer-based virtual simulations & 2.31 & Minimal utilization \\
Online quiz and tests & 2.17 & Minimal utilization \\
\hline
\end{tabular}

Table 7 shows the technology resources utilized by the nursing faculty in the six colleges of nursing. The data reveal that power point presentation was the most highly utilized by the faculty $(\mathrm{M}=3.93)$. Audiovisual slides and files $(\mathrm{M}=3.43)$, instructional videos, procedures, and documentation $(\mathrm{M}=3.15)$, video clips $(\mathrm{M}=3.10)$, online research works and updates $(\mathrm{M}=3.08)$, and web-based assignments, projects, and activities $(M=2.96)$ were moderately utilized by the nursing faculty. Computer-based virtual simulations $(M=2.42)$ and online quiz and test $(M=1.86)$, however, were the least utilized. Overall, the nursing faculty had moderate utilization $(\mathrm{M}=2.99)$ to technology-based teaching tools. 


\section{Table 7. Summary of Extent of Utilization of the Available Technology Resources and Facilities of Nursing Faculty as Experienced by the Colleges of Nursing Students $(n=218)$}

\begin{tabular}{lll}
\hline \multicolumn{1}{c}{ ICT Tools } & Mean & \multicolumn{1}{c}{ Description } \\
\hline Powerpoint Presentation & 3.93 & High utilization \\
Videoclips & 3.10 & Moderate utilization \\
Audiovisual slides/files & 3.43 & Moderateutilization \\
Instructional videos/procedures/documentation & 3.15 & Moderate utilization \\
Online research works/updates & 3.08 & Moderate utilization \\
Web-based assignments. projects, activities & 2.96 & Moderate utilization \\
Computer-based virtual simulations & 2.42 & Minimal utilization \\
Online quiz and tests & 1.86 & Minimal utilization \\
\multicolumn{1}{c}{ Overall } & 2.99 & Moderate utilization \\
\hline
\end{tabular}

From the data, it appeared that students had enjoyed and appreciated technology integration in classroom instruction by their teachers. Student testimonies attest that they greatly benefitted from the technological advances used by their teachers in their classes. Some of the statements of the students are the following:

"Ang mga technology maka help gid sa amon especially during lectures hay nagakadigest gid namon ang lessons, daw maretain gid sa amon mind, kag indi na boring. Like for example, ang powerpoint, ang discussion, makabulig gid kag after sang pag discuss ni Sir M., gina sunod niya pa gid sang video, which is maayo gid nga makabulig retain ukon ma absorb sa amon mind. Ma tatak gid sa ulo mo. Kag sa amon mga report bala, example, paubrahun kami powerpoint, dapat may video clips gid para ma intindihan sang maayu sang mag classmates namon. Ka "catchy" gid kun may mga muni nga mga technology". (Technology has greatly helped especially during lecture because we could digest the lessons better and we could really retain them in our minds and it is less boring. Like for example, the powerpoint presentation of Sir M have helped very much in his discussions. He usually starts with a video clip which can help the students absorb the lesson better. It will leave a mark. Another example is when we make power point presentations, were asked to include video clips so that our classmates can understand better. It is very catchy if we use this kind of technology)

Other experiences shared by students show how useful technology is in enhancing learning, "Brought about by technology, makabulig gid sa akon ilabi na gid bilang estudyante. Ang tanan nga gina lecture sa classroom kag sa clinical area, tanan powerpoint kag may mga video presentation. Ako nga daan, visual learner, so dapat may amu gid ni cya kada pirme". (Technology has greatly helped me as a student. All lectures in the classroom and clinical area are in powerpoint and video presentation. As for me, I am a visual learner, so it would be good if teachers would always use those technologies).

"Ang mga lain lain nga presentation, like, powerpoint, clips sa video, audio-visual slides and files, naga pa keep sang amon interest". (The use of multiple modes, such as powerpoint presentation, videoclips, and audio-visual slides/files have made lessons interesting).

"Nanamian gid ako sang mga technology nga ini, indi lang pure lecture. Nagapabugtaw ni sa akon". (I like the use of technology, instead of just a lecture. They keep me awake!). 
"I think ang pag use sa mga nagkalain lain nga mga technologies sa classroom naga help keep my attention. So dapat, every now and then, ang aton focus is to switch man nga indi ka bala madulaan sang mga words and maka help sang attention". (I think the use of different technologies in the classroom helps keep my attention. Every now and then it is great to switch focus... it really helps sometimes to pay attention and not get lost in their words).

"Ang isa namon ka Professor, naga gamit on-line links.. ipakita niya sa amon ang clip and e illustrate niya ina, nga Makita mo gid nga gina download niya. Kag ma understand ko na dayun". (One of my Professors, uses on-line links.... he would show a clip and illustrate how he downloads them and I would understand the concepts at once).

"Ang technology makahelp actively in terms of listening. Just listen and indi ka na magworry magsulat sang every word hay ma intindihan mo gid and makabulig gid". (Technology helps you in actively listen... you can just listen to them, and you do not have to worry about writing every little word down you can actually try to understand, and it helps a lot).

In general, student's comments clearly portray great appreciation of using technology in teaching and most of the students affirmed their teachers are making an effort to try teaching with use of technology. The results of this study find support in the study of Bay (2013) that among all teaching strategies, powerpoint presentation has been always used in the classroom.

\section{Extent of Benefits to Students in the Integration of Technology in the Teaching and Learning Process}

The succeeding tables reveal data on the extent of benefit of integration of technology resources and facilities of the nursing faculty in the teaching and learning process as experienced by the nursing students.

Table 8 is the extent of benefits to students of integrating technology resources and facilities of the nursing faculty in the teaching and learning process in College A.

\section{Table 8. Extent of Benefits to Students of Integration of Technology Resources and Facilities in the Teaching and Learning Process in College A $(n=30)$}

\begin{tabular}{lcl}
\hline \multicolumn{1}{c}{ Extent of Benefits } & Mean & \multicolumn{1}{c}{ Description } \\
\hline Motivated and attentive in class & & \\
Participated lesson for the day & 3.40 & Moderately beneficial \\
Enjoyed varied learning activities & 3.20 & Moderately beneficial \\
Confident in new knowledge gained & 3.57 & Highly beneficial \\
Improved school-related requirements & 3.37 & Moderately beneficial \\
Happy with what have learned & 3.53 & Highly beneficial \\
Had better grades & 3.57 & Highly beneficial \\
Increased interest in the subject matter & 3.33 & Moderately beneficial \\
Allowed greater control of class activities & 3.37 & Moderately beneficial \\
Helped in communication and collaboration & 3.43 & Moderately beneficial \\
\hline
\end{tabular}

The benefits of integration of technology among the nursing students in College A found the use of technology highly beneficial in helping them in communication and collaboration $(\mathrm{M}=3.73)$ and improving school-related requirements $(\mathrm{M}=3.53)$. They were also enjoying varied learning activities $(M=3.57)$, and happy with what they have learned 
$(\mathrm{M}=3.57)$. These were among the most mentioned benefits the students' gained from the use of technology by the faculty, however, the students were motivated and attentive in class $(M=3.40)$, participated lesson for the day $(M=3.20)$, confident in new knowledge gained $(M=3.37)$, had better grades $(M=3.33)$, increased interest in the subject matter $(\mathrm{M}=3.37)$, and allowed grater control of class activities (3.43), showed moderately beneficial.

The data on Table 9 show that the extent of benefits of integration of technology resources and facilities of nursing faculty in College B is highly beneficial to nursing students in the areas of participation in the lessons for the day $(\mathrm{M}=3.55)$ and improving school-related requirements $(M=3.59)$. The rest of the areas were moderately beneficial such as motivated and attentive in class $(\mathrm{M}=3.32)$, enjoyed varied learning activities $(\mathrm{M}=3.36)$, confident in new knowledge gained $(\mathrm{M}=3.32)$, happy with what have learned $(M=3.45)$, had better grades $(M=3.23)$, increased interest in the subject matter $(M=3.23)$, allowed greater control of class activities $(\mathrm{M}=3.41)$, and helped in communication and collaboration $(\mathrm{M}=3.45)$.

\section{Table 9. Extent of Benefits to Students of Integration of Technology Resources and Facilities in the Teaching and Learning Process in College $B$ $(n=37)$}

\begin{tabular}{lll}
\hline \multicolumn{1}{c}{ Extent of Benefits } & Mean & \multicolumn{1}{c}{ Description } \\
\hline Motivated and attentive in class & 3.32 & Moderately beneficial \\
Participated lesson for the day & 3.55 & Highly beneficial \\
Enjoyed varied learning activities & 3.36 & Moderately beneficial \\
Confident in new knowledge gained & 3.32 & Moderately beneficial \\
Improved school-relatedrequirements & 3.59 & Highly beneficial \\
Happy with what have learned & 3.45 & Moderately beneficial \\
Had better grades & 3.23 & Moderately beneficial \\
Increased interest in the subject matter & 3.23 & Moderately beneficial \\
Allowed greater control of class activities & 3.41 & Moderately beneficial \\
Helped in communication and collaboration & 3.45 & Moderately beneficial \\
\hline
\end{tabular}

The data further show that the nursing students in College $\mathrm{C}$ found the use of technology highly beneficial in the teaching and learning process. The greatest benefits of technology-based instruction as demonstrated by the highest mean scores were making them happy with their learning $(\mathrm{M}=3.78)$, it had helped the students in communication and collaboration $(\mathrm{M}=3.68)$, and it had made students more interested in performing school-related requirements $(\mathrm{M}=3.59)$. The students were also confident in the new knowledge gained $(\mathrm{M}=3.54)$ and they were more motivated and attentive during classes $(\mathrm{M}=3.51)$.

The contribution of the use of technology in the students' extent of participation in class $(M=3.38)$ and in obtaining better grades $(M=3.30)$, were the least mentioned among the benefits of technology in the teaching and learning process, as they obtained the lowest mean scores. Anyhow, the students still recognized that technology is highly beneficial in the student's learning. 


\section{Table 10. Extent of Benefits to Students of Integration of Technology Resources and Facilities in the Teaching and Learning Process in College C $(n=37)$}

\begin{tabular}{lll}
\hline \multicolumn{1}{c}{ Extent of Benefits } & Mean & \multicolumn{1}{c}{ Description } \\
& & \\
\hline Motivated and attentive in class & 3.51 & Highly beneficial \\
Participated lesson for the day & 3.38 & Moderately beneficial \\
Enjoyed varied learning activities & 3.57 & Highly beneficial \\
Confident in new knowledge gained & 3.54 & Highly beneficial \\
Improved school-related requirements & 3.59 & Highly beneficial \\
Happy with what have learned & 3.78 & Highly beneficial \\
Had better grades & 3.30 & Moderately beneficial \\
Increased interest in the subject matter & 3.46 & Moderately beneficial \\
Allowed greater control of class activities & 3.41 & Moderately beneficial \\
Helped in communication and collaboration. & 3.68 & Highly beneficial \\
\hline
\end{tabular}

The data in Table 11 further reveal that the nursing students in College D found that the use of technology by their teachers in the teaching and learning process was found to be moderately beneficial in all areas to students. The ICT tools had motivated them to be more attentive in class $(M=3.47)$, had brought happiness with their learning $(M=3.39)$, had helped in communication and collaboration $(\mathrm{M}=3.39)$, they became active in the lessons for the day $(M=3.34)$ and had enjoyed varied learning activities ( $M=3.34)$. Moreover, the students were confident in the new knowledge gained $(M=3.24)$, and had helped them in improving their grades $(M=3.21)$. The use of technology had also brought greater control of class activities $(\mathrm{M}=3.18)$ and enabled students to get better grades $(M=3.08)$. In all, the means scores indicate that the students recognized the moderate benefits in the usage of technology in the teaching and learning process.

Table 11. Extent of Benefits to Students of Integration of Technology Resources and Facilities in the Teaching and Learning Process in College D $(n=38)$

\begin{tabular}{lcc}
\hline \multicolumn{1}{c}{ Extent of Benefits } & Mean & Description \\
\hline Motivated and attentive in class & 3.47 & Moderately beneficial \\
Participated lesson for the day & 3.34 & Moderately beneficial \\
Enjoyed varied learning activities & 3.34 & Moderately beneficial \\
Confident in new knowledge gained & 3.24 & Moderately beneficial \\
Improved school-related requirements & 3.21 & Moderately beneficial \\
Happy with what have learned & 3.39 & Moderately beneficial \\
Had better grades & 3.08 & Moderately beneficial \\
Increased interest in the subject matter & 3.34 & Moderately beneficial \\
Allowed greater control of class activities & 3.18 & Moderately beneficial \\
Helped in communication and collaboration & 3.39 & Moderately beneficial \\
\hline
\end{tabular}

The data further show that in College E, the use of technology by the teachers was highly beneficial to the students. The highest mean scores show that utilization of technology had improved school-related requirements $(M=3.70)$, had helped them in communication and collaboration $(\mathrm{M}=3.65)$, and they were happy and enjoyed much of their learnings ( $M=3.65$ and 3.65, respectively). The effect of the use of technology in the class participation $(\mathrm{M}=3.25)$ obtained the lowest mean scores, however, the score is still equivalent to "moderately beneficial". 
Table 12. Extent of Benefits to Students of Integration of Technology Resources and Facilities in the Teaching and Learning Process in College $E$ $(n=20)$

\begin{tabular}{lll}
\hline \multicolumn{1}{c}{ Extent of Benefits } & Mean & \multicolumn{1}{c}{ Description } \\
& & \\
\hline Motivated and attentive in class & 3.30 & Moderately beneficial \\
Participated lesson for the day & 3.25 & Moderately beneficial \\
Enjoyed varied learning activities & 3.55 & Highly beneficial \\
Confident in new knowledge gained & 3.45 & Moderately beneficial \\
Improved school-related requirements & 3.70 & Highly beneficial \\
Happy with what have learned & 3.65 & Highly beneficial \\
Had better grades & 3.40 & Moderately beneficial \\
Increased interest in the subject matter & 3.55 & Highly beneficial \\
Allowed greater control of class activities & 3.55 & Highly beneficial \\
Helped in communication and collaboration & 3.65 & Highly beneficial \\
\hline
\end{tabular}

Table 13 shows that extent of benefits of integrating technology resources and facilities in the teaching and learning process by the nursing students in College $\mathrm{F}$. The highest mean scores obtained were recorded for the following benefits: it made the students happy $(M=3.61)$, it helped students to enjoy class $(M=3.49)$, and it made them interested in school activities $(\mathrm{M}=3.48)$. Moreover, the use of technology had helped students get better grade $(\mathrm{M}=3.01)$ and allowed control of class activities may have obtained the lowest mean scores, but the values are still equivalent to "moderately beneficial".

Table 13. Extent of Benefits to Students of Integration of Technology Resources and Facilities in the Teaching and Learning Process in College $F$ $(n=71)$

\begin{tabular}{lcl}
\hline \multicolumn{1}{c}{ Extent of Benefits } & Mean & Description \\
\hline Motivated and attentive in class & 3.34 & Moderately beneficial \\
Participated lesson for the day & 3.28 & Moderately beneficial \\
Enjoyed varied learning activities & 3.49 & Moderately beneficial \\
Confident in new knowledge gained & 3.42 & Moderately beneficial \\
Improved school-related requirements & 3.48 & Moderately beneficial \\
Happy with what have learned & 3.61 & Highly beneficial \\
Had better grades & 3.07 & Moderately beneficial \\
Increased interest in the subject matter & 3.30 & Moderately beneficial \\
Allowed greater control of class activities & 3.21 & Moderately beneficial \\
Helped in communication and collaboration & 3.32 & Moderately beneficial \\
\hline
\end{tabular}

In all, the use of technology made the students happy with their learning $(\mathrm{M}=3.58)$ and had helped in communication and collaboration $(M=3.50)$. The lowest mean scores, but were still equivalent to a moderately beneficial, wherein the use of technology had helped the students in participating the lessons for the day $(\mathrm{M}=3.32)$ and in having better grades $(M=3.19)$. The over-all result show moderate extent of benefit of the integration of technology resources and facilities by the nursing faculty in teaching and learning process. This means that the use of technology enhances students' motivation to learn and are more likely to have enjoyable and meaningful learning experiences. Technology integration in the teaching and learning benefits the students in numerous ways in their quest for life-long learning. 


\section{Table 14. Summary of Extent of Benefits to Students of Integration of Technology Resources and Facilities in the Teaching and Learning Process $(n=218)$}

\begin{tabular}{lll}
\hline \multicolumn{1}{c}{ Extent of Benefits } & Mean & \multicolumn{1}{c}{ Description } \\
\hline Motivated and attentive in class & 3.39 & Moderately beneficial \\
Participated lesson for the day & 3.32 & Moderately beneficial \\
Enjoyed varied learning activities & 3.48 & Moderately beneficial \\
Confident in new knowledge gained & 3.39 & Moderately beneficial \\
Improved school-related requirements & 3.49 & Moderately beneficial \\
Happy with what have learned & 3.58 & Highly beneficial \\
Had better grades & 3.19 & Moderately beneficial \\
Increased interest in the subject matter & 3.36 & Moderately beneficial \\
Allowed greater control of class activities & 3.32 & Moderately beneficial \\
Helped in communication and collaboration & 3.50 & Highly beneficial \\
\multicolumn{1}{c}{ Overall } & 3.40 & Moderately beneficial \\
\hline
\end{tabular}

The following are the excerpts from the focus group discussion in terms of the benefits of the technology integration to the nursing students.

"Ang paggamit sang mga downloadable nga animation, makabulig gid connect and communicate sa topic materials. Makita mo gid ang diagram nga indi mo na bala pag e figure out kun anu ila ginahambal". (The use of downloadable animation had helped in making connections and communications with the topics. You can see the diagram so you don't have to try to figure out what they are talking about).

"Nasadyahan gid ako sang mga technologies nga ini hay nakabulig gid visualize nga indi mo makita sa libro, ginabasa mom o man ukon nabatian". (I am happy with technology because it really helps to visualize things that you wouldn't get out of reading a book or by hearing them).

One of the students verbalized that, "Sa amon nga lecture, ang mga technologies nga ini makabulig hatag sang mga major points which improved my confidence". (During lecture, technology helps you bring home major points which have helped to increase my confidence).

"Helpful gid katama ang mga technology na ini, like when doing research, dapat reliable gid ang mga resources which nagapa help improve sang amon mga grades. And sa amon quizzes, grabe gid ang pagbulig sa amon performance which brings about easy recall of a certain topic". (Technology like this can be very helpful especially in doing research. Resources should be reliable which can help us improve our grades. In our quizzes, technology has greatly helped in improving our performance because it brings about easy recall of certain topics).

"Grabe gid ang pag bulig improve academically sang mga technology nga ini, like gina enhance niya gid ang imo pag intindi sang mga topics nga indi mu kun kaisa maunderstand kun gina read mo lang". (Technology has greatly helped us improve academically. It enhances our understanding of topics that otherwise we may not understand if we only read about it in our textbooks).

"In terms of grades, grabe ang na help sa akon. Na enhance gid ang akon audiovisual perception, especially kun mag exams kami nga ma recall ko gid ya tanan tanan. As in, very clear gid". (In terms of grades, it has greatly helped me. It enhanced my 
audio-visual perception especially during exams because I can easily recall all lessons clearly).

The students expressed that the use of technology greatly enhances their learning and it was highly beneficial to them. This was supported by Kandeel and Ibrahim (2010) that nursing students had a positive perception on the impact of using IT on teaching and learning.

\section{Summary of Findings}

1. The extent of utilization of the available technology resources and facilities of nursing faculty was moderate $(M=2.99)$. Powerpoint presentation was highly utilized and the computer-based virtual simulations and online quiz and test, however, were the least utilized.

2. The extent of benefit to students in the integration of technology by the nursing faculty in teaching and learning process was moderate. The integration of technology made the students happy, allowing them to enjoy varied learning activities, and has helped in communication and collaboration.

\section{Conclusion}

This research study concludes that the integration of technology can make a measurable difference in teaching and in the learning process. Technology integration in the teaching and learning benefits the students in numerous ways in their quest for lifelong learning. The utilization of technology enhances students' motivation to learn and are more likely to have an enjoyable and meaningful learning experiences.

The research evidence confirms that the constructivist learning environments and innovations, representing that learning with technology, which encourages learners to actively process and organize information by making internal cognitive connections, can well provide the theoretical framework for effective technology integration. Recommendations focused on enhancement capability-building programs in utilizing technology, creative lesson planning and blended learning, improving school resources and facilities, and adaptation to technological use in nursing education.

\section{References}

[1] Division of Higher Education, United Nations Educational, Scientific, and Cultural Organization, "Information and communication technology in education: a curriculum for schools and programme of teacher development", (2002).

[2] J.L. Fernández-Alemán, A.B. Sánchez, M.J. López, P. Marqués-Sánchez, E. Darkistade, \& F.J. Pérez, "Exploring the use of information and communication technologies and social networks among university nursing faculty staff: an opinion survey", Invest Educ Enferm, vol. 32, no. 3, (2014), pp. 438450.

[3] L. Axley, "The integration of technology into nursing curricula: supporting faculty via the technology fellowship program", OJIN: The Online Journal of Issues in Nursing, vol. 13, no. 3, (2008).

[4] L. Iverson, S. Ball, A. Harms, C. Murcek, S. Woods, \& T. Young (2016), "Technology in the College of Nursing: perception and use to achieve learning outcomes. Online Journal of Nursing Informatics (OJNI), 20 (1), Available at http://www.himss.org/ojni, (2016).

[5] M. Stec, "Technology integration into nursing education: a case study in higher education", Retrieved July 21, 2017 from http://www.nursinglibrary.org.

[6] J.M. Brown, "Does the use of technology in the classroom increase students' overall academic performance? "Masters' Thesis, Gonzaga University, (2011).

[7] B. Bay, "Integration of technology-driven teaching strategies for enhancing photojournalism course", Educational Research International, vol. 2, no. 2, (2013).

[8] M. Al-Hariri \& A. Al-Hattami, "Impact of students' use of technology on their learning achievements in physiology courses at the University of Dammam", Journal of Taibah University Medical Sciences, vol. 12, no. 1, (2017), pp. 82-85. 
[9] N. Kandeel \& Y. Ibrahim, "Student nurses' perception on the impact of information technology on teaching and learning", International Journal of Information and Communication Technology Education", vol. 6, no. 3, (2010), pp. 38-50.

\section{Author}

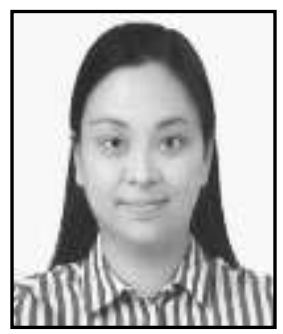

Mae Joy P. Espinosa, PhD, RN is an Assistant Professor in Woosong University, Daejeon, Republic of Korea. She had been a Lecturer in the Department of Adult and Critical Care, College of Nursing, Sultan Qaboos University, Muscat, Oman. She has made significant contributions to patient care through teaching, lectures, leadership activities, and professional activities both in graduate and undergraduate nursing. 
International Journal of Advanced Science and Technology

Vol.110 (2018) 